\title{
UX and Strategic Management: A Case Study of Smartphone (Apple vs. Samsung) and Search Engine (Google vs. Naver) Industry
}

\author{
Junho Choi ${ }^{1}$, Byung-Joon $\mathrm{Kim}^{2}$, and SuKyung Yoon ${ }^{1}$ \\ ${ }^{1}$ UX Lab., Yonsei University, Seoul, S. Korea \\ junhochoi@yonsei.ac.kr, skyoon24@gmail.com \\ ${ }^{2}$ SK Institute of Management \& Economics, Seoul, S. Korea \\ spike.ipiegel@gmail.com
}

\begin{abstract}
This paper extends the analytic framework of user experience design into the area of strategic management by adopting the VRIO framework. We adopted value-rarity-imitability-organization (VRIO) framework and applied this integrated scheme into the investigating market cases. The first case study is the analysis of competitive advantages of two successful smartphone device makers, Apple (iPhone) and Samsung (Galaxy). UX Values (attractive design, ease of use, diverse applications), Rarity (simplicity, innovative interface, ecosystem), Imitability (patent, brand identity), and Organization (UX control tower, role of CXO) are employed to analyze and compare the strategies of those two most successful smartphone makers. In the second case study we compared the UX strategies of Google and Naver in the global and local levels. Through the case studies this paper shows a strong implication that UX can be extended into the corporate resources and capability, and VRIO framework utilized for the analysis of competitive advantages for the market leadership.
\end{abstract}

Keywords: User experience design, Strategic management, VRIO framework, Apple, Samsung, Google, Naver.

\section{Introduction: VRIO Framework for UX Design Strategy}

Since the revolutionary success of Apple, the competitive advantage of most ICT products and services in the contemporary market is now gained from the domain of user experience (UX) beyond the functionality and efficiency. Witnessing the market failure of companies who didn't pay much attention to the user-oriented design, e.g., Nokia, Motorola, RIM(Blackberry), and SONY, there has been, however, a little effort to explore the analytic framework for competitive advantage of UX design in terms of the strategic management.

Strategic management seeks analyses and choices to gain competitive advantages (Barney \& Hesterly, 2012). That is, the goal of corporate management is the generating the competitive advantages over other companies in the market. It is the strategy that is the process of determining the best solution to achieve the goal.

Market leadership, or competitive advantage, is determined by how effectively the company creates more economic values of its products and services than those of 
competitors.' Consequently, the economic values in the market is appraised by how much consumers get the benefit out of the experiential use of the products and services.

The outcomes of competitive advantages in the market are not only the profit maximization but also sustainability of the corporation (Porter, 2008). Definitely, profit maximization through the consumers' heightened value perception of products is the basic management performance standard in most of corporations. However, witnessing the market failure of once glorious, dominant, innovative companies such as Nokia, SONY, Motorola, RIM, Dell, and Microsoft, we believe that long-term sustainability is also an important management performance goal in this fast changing ICT market.

\section{VRIO Framework}

When a corporation sets and implements strategies to achieve profit and sustainability, it is necessary to establish a framework for analysis, decision making, and evaluation of possible strategies. The VRIO framework (Barney \& Hesterly, 2012) posits that the resources and capabilities are the core components of strategic management process. The VRIO framework helps to provide analytic and systematic answers to those questions: 1) Does a resource enable a firm to utilize the opportunity and neutralize a threat?; 2) Is a resource currently controlled by only our company or by only a small number of competing firms?; 3) Do other firms without the resource face disadvantages in obtaining or developing it?; and 4) Are our firm's values, procedures, structures organized to support the actualization of its valuable, rare, and costly-to imitate resources?

Focusing on the product quality differentiation, rather than on the cost differentiation, we applied the VRIO framework into the User Experience Design. Table 1 shows the summary.

Table 1. VRIO Framework for UX

\begin{tabular}{|c|c|c|}
\hline Component & Evaluation Criteria (question) & $\begin{array}{l}\text { Example: Apple's iPhone (mainly on } \\
\text { the introduction of 3GS in 2009) }\end{array}$ \\
\hline Value & $\begin{array}{l}\text { Does our product have UX } \\
\text { values that consumers perceive } \\
\text { as competitive edge over other } \\
\text { products? }\end{array}$ & $\begin{array}{ll} & \text { Attractive design } \\
- & \text { Ease of use } \\
- & \text { Diverse applications }\end{array}$ \\
\hline Rarity & $\begin{array}{l}\text { Are those UX values provided } \\
\text { only by our product and per- } \\
\text { ceived as rare by consumers? }\end{array}$ & $\begin{array}{ll}\text { - } & \text { Simplicity } \\
\text { - } & \text { Completeness } \\
\text { - } & \text { Platform \& App Store } \\
\end{array}$ \\
\hline Imitability & $\begin{array}{l}\text { Do other companies have diffi- } \\
\text { culties with copying or develop- } \\
\text { ing those UX values? }\end{array}$ & $\begin{array}{ll}- & \text { Interface design patent } \\
\text { - Seamless multi-device coordina- } & \text { tion (iPad, iPod) } \\
\text { - Brand Identity (Cultural icon of } \\
\text { Innovation) }\end{array}$ \\
\hline Organization & $\begin{array}{l}\text { Are our firm organized effec- } \\
\text { tively to utilize those valuable, } \\
\text { rare, and costly-to imitate re- } \\
\text { sources? }\end{array}$ & $\begin{array}{l}\text { - } \quad \text { Corporate level UX control tower } \\
\text { - Charismatic leadership and deci- } \\
\text { sion making }\end{array}$ \\
\hline
\end{tabular}




\section{Case Study \#1: Apple vs. Samsung}

The first case study is the analysis of competitive advantages of two successful smartphone/tablet device makers, Apple (iPhone) and Samsung (Galaxy). The collapse of Nokia and Motorola in the smartphone market clearly demonstrates that market failure can be caused by the weaknesses in the value creation, differentiation, market barrier, and organizational structure/processes of UX resources in the company and its products. Representing the first mover and the fast follower of smartphone makers, the VRIO analysis of Apple and Samsung presents a very interesting and insightful case study of UX's contribution to the competitive advantage for the corporation.

Most of HCI pundits and even average users believe that Apple is the most advanced company in terms of user experience design. The brand image of "easy, simple, and attractive" has been accumulated from the earlier personal computers with GUI, that is LISA(1983) and McIntosh(1984). Actually, iPod(2001) and iPhone $3 G S(2009)$ were the first products of Apple which achieved market leadership and competitive advantage in the music and in the mobile phone industries, respectively. Those groundbreaking impacts on the ICT market have made UX perceived as the most critical component of the revolutionary success of Apple (Banjarin, 2012).

What are the Apple's own UX strategies which generated the new entrant's landsliding advantage over preexisting competitors? Generally, Apple's UX capacities are summarized as three points:

1. Minimalism or Simplicity: Apple is perceived as the most progressive company, but has been conservative in adding features. That is, "less (feature) is more (user experience)" has been Apple's consistent strategy. Most IT manufacturers tend to keep preexisting features and add additional features in the new product, which sometimes creates the 'feature creep' or the complexity. However, for example, Apple did not install radio feature in the iPod until 2009 (Isaacson, 2011).

2. User segmentation by skill level: Most companies utilize user segmentation by demographic categories or lifestyle groups. However, for simplicity and ease of use, Apple has applied novice-experienced user segmentation into every aspect of the interaction design such as information architecture and interfaces (Baty, 2009). Basic features can be learned instinctively by novice users and the cognitive overflow of information was restricted. Advanced features are usually hidden but the setting options can be found by experienced users, often generating a 'surprise effect'.

3. Coherence of user experience (same UX, different UI): Since many users are surrounded by multiple devices, e.g., PC, TV, tablet, MP3 player, and smartphone, and they sometimes use them simultaneously or consecutively. The N-screen environment creates 'distributed interaction' (Reeves et al, 2004) or multi-devices experiences. The complex environment always requires a seamless integration of UX design of multi-device usage. Beyond embedding the same OS and consistent interface styles, Apple set the design strategy for integrating the different screen sizes and use contexts of each devices, thus ended up with providing.

UX Values (e.g., attractive design, ease of use, diverse applications), Rarity (e.g., simplicity, innovative interface, ecosystem), Imitability (e.g., patent, brand identity), and Organization (e.g., UX control tower, role of CXO) are employed to analyze and compare the strategies of those two most successful smartphone makers in the global market. 
When a Samsung's rivalry smart phone with Windows 6.0 OS (Haptic 2) was miserably defeated by iPhone 3GS even in the domestic market of S. Korea, its sustainability in the smartphone market was not anticipated by most market analysts and HCI experts. Poor UX design of their TouchWiz interface was blamed for the main reason of the market failure.

However, Samsung implemented successfully a fast follower strategy and, in a relatively short time period, gained the market leadership by enlarging the gaps between competitors in Android OS smartphone industry. Their fast recovery of market competence can be explained well by VRIO framework. The Android OS was open to all competitors, so basic features were not the differentiating values. Samsung absorbed the UX principles and design details of the market leader, Apple, and quickly improved the satisfaction level of user experience. Taking full advantages of manufacturing resources and capabilities, the mobile division of Samsung Electronics offered diverse line-ups by inch-by-inch screen sizes. Not all of them were survived, but 5 and 6 inch screens were accepted by market. For the large screen phones (Galaxy Note \& Tab), they applied UX differentiation strategy by adding stylus pen and drawing interactions. The 4 inch screen and no-stylus pen were Apple's UX strategy for giving users the comfortable feeling of grip and minimal interaction, but a better visibility in a larger screen and a notetaking with an always carrying mobile device were the rare values that Samsung intended to create for diversely segmented phone users.

Table 2. VRIO Framework of UX Strategies: Apple vs. Samsung

\begin{tabular}{|c|c|c|}
\hline component & Apple (iPhone) & Samsung (Galaxy) \\
\hline Value & $\begin{array}{l}\text { - Simplicity } \\
\text { - Ease of Use } \\
\text { - Attractive Design }\end{array}$ & $\begin{array}{l}\text { - Ease of Use } \\
\text { - Diverse line-ups by screen sizes }\end{array}$ \\
\hline Rarity & $\begin{array}{l}\text { - Own app/content platform } \\
\text { (AppStore \& iTunes) } \\
\text { - Seamless integration of } \\
\text { multiple devices(iPhone, iPad, } \\
\text { iTV) through iCloud }\end{array}$ & $\begin{array}{l}\text { - Customized version for carriers } \\
\text { - UX Differentiation (stylus pen } \\
\text { for Galaxy Note) } \\
\text { - Development of own OS and } \\
\text { platform (Bada and Samsung } \\
\text { Store) }\end{array}$ \\
\hline Imitability & $\begin{array}{l}\text { - Design \& interface patent } \\
\text { - Brand image of 'innovative } \\
\text { and simple UX' }\end{array}$ & $\begin{array}{l}\text { - Brand image of 'technological } \\
\text { edge of UX' }\end{array}$ \\
\hline Organization & $\begin{array}{l}\text { - UX control tower (role of } \\
\text { CXO: Steve Jobs) } \\
\text { - Consolidated accounting } \\
\text { system }\end{array}$ & $\begin{array}{l}\text { - Independent design center } \\
\text { - Internal competition among } \\
\text { design teams }\end{array}$ \\
\hline
\end{tabular}

Also, Samsung's attempt to build their own OS(Bada) and app store (Samsung Apps) was not successful in the market, but the trial and error contributed to the UX differentiation through activation of UX R\&D and internalization of UX-oriented decision making 
procedure. Instead of Apple's integrative brand image of 'innovation' and 'simplicity,' Samsung initially pursued differentiating brand identity of 'technological edge.' Later, they changed their marketing strategy toward more human-centered image through massive UX-oriented marketing campaigns.

In order to maintain the competitive edge in the UX, it is necessary to develop internal organizational structure, decision making procedure, corporate culture, and performance evaluation metrics. In lack of Apple's creative and hegemonic star CEO, Steve Jobs, who governed all aspects of product and service UX strategies with a small number of design creative team (Lashinsky, 2012), Samsung utilized a hierarchical organization structure in order to maximize their design capacities. They scouted UX specialists from universities and other companies, expanded the design center, and founded overseas UX research centers (e.g., UX Innovation Lab, UX Mobile Lab, UX Services Lab, Visual Display UX Lab in the Silicon Valley).

\section{Case Study \#2: Google vs. Naver}

The second case study is about the search engine/portal industry. Google has gained the market monopoly in all countries with only two exceptions: Baidu in China and Naver in S. Korea (Yahoo Japan is now affiliated with Google search engine). Considering the socialist political system of China, the Naver is the single case of market winner over Google on the glove.

Utilizing the VRIO framework, we compared the competitive advantages of Google's and Naver's UX strategies in the global and local levels. The case study of Naver in S. Korea demonstrates well that UX design can be critical resources for management strategies in the local market where domestic players are faced with fierce competition with global ones. Strategies for localization of interface designs and taming of local user experiences have led to the familiarity with the local brand and distinctive interaction styles.

Compared to Google's simplicity, usefulness, consistency values originated from the sophisticated high-tech search engine algorithm, Naver's strategies for market competition were internalization of online information in terms of content generation, tagging, selection, and display, heavily dependent on human labors and exclusive contracts with content sources.

Naver's closed walled-garden ecosystem contrasts clearly with the Google's open eco-system, and the local service's competitive edge was gained from the rarity and difficult imitability of UX strategies. For example, regardless of disputes and blames over openness spirit of the Internet, Naver had blocked their webpages from indexing by other search engines. In leveraging of the network effect, i.e., the economic law of 'the rich get richer,' Naver outpaced once a dominant competitor, Daum Communications, but the strategy was different from the market leadership transition from Yahoo to Google. Limiting the range of information accessibility, instead, Naver attracted S. Korean Net users by providing the one-stop \& all-in-one solution of culturally customized information needs. The domesticated convenience and ease of use have made online users familiar with their localized interaction mode and interface styles. A local subsidiary of Google once launched a massive publicity campaign but in vain for changing the user habits. Because Google runs global service, their localization 
strategy often conflicts with global brand identity and lacks corporate capabilities for localization.

Also, for the sustainability and brand identity, the company has built a unique organizational structure and internal process of UX: the top level managerial decision making by combining research, design, marketing units into one and by CXO's presence in the de facto control tower.

Table 3. VRIO Framework of UX Strategy: Google vs. Naver

\begin{tabular}{|c|c|c|}
\hline component & Google & Naver \\
\hline Value & $\begin{array}{l}\text { - Simplicity, usefulness, con- } \\
\text { sistency }\end{array}$ & - Localization of interface design \\
\hline Rarity & - Diverse \& useful services & - Walled-garden content system \\
\hline Imitability & $\begin{array}{l}\text { - Brand image of "the most } \\
\text { useful \& technological edge" }\end{array}$ & $\begin{array}{l}\text { - Brand image of "local familiari- } \\
\text { ty" }\end{array}$ \\
\hline Organization & $\begin{array}{l}\text { - Hidden UX control tower for } \\
\text { maintaining simplified homep- } \\
\text { age and brand identity }\end{array}$ & $\begin{array}{l}\text { - CXO's presence in the control } \\
\text { tower: consolidation of research, } \\
\text { development, design, and market- } \\
\text { ing }\end{array}$ \\
\hline
\end{tabular}

\section{Conclusion and Discussions}

Applying VRIO framework into two case studies, we attempted utilization of strategic management for the UX design. The market failure and the collapse of Nokia and SONY clearly demonstrate why the UX as a practice requires management viewpoint.

SONY illustrated well the importance of UX management in the era of convergence. Ando Kunitake, the global IT market leader Sony's CEO in 2001, proposed the concept of 'ubiquitous value network' and addressed that "new technology needs to drive people into the world in which information and data can be accessed anywhere, using any type of personal devices." (Comdex Keynote Speech, 2001. http://edition.cnn.com/2001/TECH/ptech/11/12/comdex.sony.keynote/index.html).

SONY's new strategy implemented with the alliances with Ericsson and the combination of PC, laptop, game console, digital camera, phone, and wristwatch. Already, they had entertainment content resources to deliver over their devices through music (CBS Records) and movie (Columbia Pictures) studios.

Most pundits believed at that time that SONY's convergence strategy was the right way to lead the future market and it had enough resources and capabilities. They made Walkerman, VCR, camcorder, CD player and their brand was perceived as the most innovative and reliable. Also, their design capability had been acclaimed every year at Red Dot awards.

In 2014 the portrait of once most valuable brand, SONY, is far behind the prospect. Their smartphones are not perceived as popular or luxurious in the outside of domestic market. Global market share of their smartphone has not surpassed 5\% since the introduction of Xperia series. Other products such as TV, laptop, media players lost 
market leadership over once second-tier manufacturers such as Samsung, Apple, and Lenover. Many pundits expect now their little chance of coming back to the market leadership.

The main reason of SONY's losing competitive advantage in the ICT industry lies in the failure of UX strategy for changing market paradigm. Their past success history in the era of supply demand market made SONY blinded from the poor user encounters with their products and services, in other words, the 'moment of truth' (Norman, 1984). Each product still has top level technological edges and design aesthetics. However, they failed to create the satisfactory easy to use and integrative user touch points that consolidate user experience of using their multiple devices. They proposed the convergence of contents and devices, but users couldn't perceive expected level of coherence when using SONY products and services. For example, SONY's Xross Media Bar (XMB) interface extended the consistent UI into PlayStation, Bravia HDTV, VAIO laptop, Xperia smartphone, but failed to create an integrative platform for the users. Most users felt frustrations with the points of access to the content and to other devices they wanted to use. The innovation of 'ubiquitous value network' they pursued was just technology- and design-oriented, not user-oriented. SONY had not operated a corporate level UX control tower and CXO position until punitive resignation of managerial board in 2011.

Here is another example of UX strategy failure: Nokia, the first smartphone maker (Nokia 7650 in 2002), had been renowned for their global R\&D and technological innovation capabilities. Their industry leading leadership in the highly competitive mobile phone market also came from the outstanding global sourcing and supply chain management capabilities.

The dramatic falling down of the once dominant and glorious company in the mobile market began with the small cracks in the differentiating values of smartphone user experience that their products provided for changing users after the new market entrants such as iPhone and Galaxy. Nokia's competing products, e.g., N5800, were optimized for past feature phone user experience: users had a terrible usability and awkward experiences of screen touch interface tuned for hard key pressing. Nokia had global top level UX design practitioners but their valuable human resources fail to generate capabilities for competitive advantages in the market.

Most pundits accuse managerial decision making procedure in the organization of the market failure and user dissatisfaction. Olli-Pekka Kallasvuo, the new CEO in 2006, combined the new smartphone division into the incumbent feature phone division. In spite of the fast changing user experiences in mobile market, top decision makers kept concentrating cash-cow old products and neglected the upcoming threats and opportunities. Due to lack of UX oriented decision making and organizational structure, the design head, Alastair Curtis, had difficulties to implement coherent usability and aesthetic impression in a series of products as Apple showed for their brand identity. Proposed improvements of interface and interaction prototypes were twisted in the tension between internal teams of Symbian and Mago, deterred by user research from globally distributed labs with unstandardized methods, and finally turned down by business division for a short term operation profit. Thus, Nokia failed to manage UX oriented organization and to gratify the market needs of user experience. The once global market leader of mobile industry lost their capability of sustainability and finally ended up with merger by Microsoft in 2013. 
Supported both from the the market failure examples and from success cases, we argue that UX should be regarded as core resources and capabilities of the corporation in order to gain competitive advantage in this demand-side market of ICT industry. Every decision making on the interaction and interface designs should be considered as a management strategy. It does not mean that UX practitioners should work under the managerial guidelines for short-term profit making. What we think important is that the corporate managers should work under the user experience guidelines for sustainability and brand identity. Here are future agenda: Applying strategic management into the UX requires further investigation and refinement in standardization of UX ROI evaluation and optimization of UX practitioners' expanding roles in the organization.

\section{References}

1. Barney, J.B., Hesterly, W.S.: Strategic Management and Competitive Advantage, 4th edn. Pearson Education (2012)

2. Bajarin, T.: 6 Reasons Apple Is So Successful. Time, May 07, 2012 (2012),

http: //techland.time.com/2012/05/07/

six-reasons-why-apple-is-successful/

3. Baty, S.: Audience Segmentation Models. UX Matters (September 21, 2009),

http: / /www . uxmatters.com/mt/archives/2009/09/

audience-segmentation-models.php

4. Isaacson, W.: Steve Jobs. Simon \& Schuster (2011)

5. Lashinsky, A.: Inside Apple: How America's Most Admired - and Secretive - Company Really Works. Business Plus (2012)

6. Norman, R.: Service Management: Strategy and Leadership in the Service Business. John Wiley \& Sons (1984)

7. Porter, M.: Competitive Advantage: Creating and Sustaining Superior Performance. The Free Press (1998)

8. Porter, M.: On Competition, updated and expanded edition. Harvard Business School Publishing Corporation (2008)

9. Reeves, L.M., et al.: Guidelines for multimodal user interface design. Communications of ACM 47(1), 57-59 (2004) 